\section{Pituitary adenylate cyclase activating polypeptide}

R. Tauber und F. H. Perschel

Institut für Laboratoriumsmedizin, Klinische Chemie und Pathobiochemie, Charité - Universitätsmedizin Berlin

Campus Virchow-Klinikum, Berlin, Deutschland

\section{Synonym(e) PACAP}

Englischer Begriff pituitary adenylate cyclase-activating polypeptide

Definition Pituitary adenylate cyclase activating polypeptide ist ein Neuropeptid, das aufgrund von Strukturähnlichkeit einer Superfamilie zugerechnet wird, der auch $>$ Vasoaktives Intestinales Polypeptid (VIP), \ Glukagon, Growth Hormone Releasing Factor (GRF) und $\triangleright$ Sekretin angehören.

Beschreibung PACAP wurde im Jahr 1989 erstmals aus Hypothalamusgewebe extrahiert und kurz danach als Peptid mit 38 Aminosäuren $\left(\mathrm{PACAP}_{38}\right)$ identifiziert. Aus dem PACAP-Vorläuferpeptid kann außerdem das biologisch ebenfalls aktive 27 Aminosäuren umfassende PACAP $_{27}$ freige- setzt werden, das dem N-terminalen Anteil des PACAP $_{38}$ entspricht und eine 68 \%ige Sequenzhomologie zu VIP aufweist. PACAP ist immunologisch in verschiedenen Bereichen des ZNS, in den meisten endokrinen Drüsen und in allen Teilen des Gastrointestinaltrakts nachweisbar. HPLCUntersuchungen haben gezeigt, dass $\mathrm{PACAP}_{38}$ hierbei gegenüber PACAP 27 überwiegt, der jeweilige Anteil jedoch gewebespezifisch unterschiedlich ist. PACAP kann in eine breite Vielfalt biologischer Prozesse, wie Reproduktion, Wachstum und Entwicklung, respiratorische und kardiovaskuläre Funktion, gastrointestinale Funktion, Immunantwort und zirkadiane Rhythmik eingreifen. In wieweit die hierbei beobachteten pharmakologischen Effekte physiologische Wirkungen widerspiegeln, ist gegenwärtig noch unklar. Die Konservierung der biologisch wirksamen Sequenz des PACAP in der Evolution vom Fisch bis zum Menschen deutet jedoch auf vitale Funktionen dieses Peptids hin.

\section{Literatur}

Vaudry D, Gonzalez BJ, Basille M et al (2000) Pituitary adenylate cyclase-activating polypeptide and its receptors: from structure to functions. Pharmacol Rev 52:269-324 